Trakya Eğitim Dergisi

Cilt 9, Sayı 4

2019 Ek Sayı

Aralık 2019, 723-741

Geliş Tarihi: 31.01 .2019

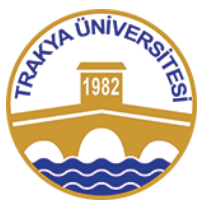

ISSN: $2630-6301$
Trakya Journal of Education

Volume 9, Issue 4

2019 Additional Issue

December 2019, 723-741

DOI: $10.24315 /$ tred.520477

Yayına Kabul Tarihi: 06.12.2019

Araştırma Makalesi

\title{
ARCS Motivasyon Modeli: 1997-2018 Yılları Arasında Yapılmış Uygulamalı Makalelerin İçerik Analizi
}

ARCS Motivation Model: Content Analysis of Applied Articles Between the Years 1997-2018

\author{
Vahit Ağa YILDIZ ${ }^{1}$, Özlem BAYDAȘ ÖNLÜ², Yüksel GÖKTAȘ³
}

\begin{abstract}
Öz: ARCS motivasyon modelinin eğitimsel kullanımına ilişkin uygulamalı makalelerin hem yöntemsel hem de içeriksel eğilimlerini belirlemeyi amaçlayan bu çalışmada, döküman analizi yöntemi kullanılmıştır. Çalışmada, Web of Science, ERIC, SCOPUS, ULAKBIM ve Google Scholar'da dizinlenen dergilerdeki 128 uygulamalı makale incelenmiş ve elektronik ortamda oluşturulan formla sınıflandırılmıștır. Calıșmalar Google Formlar ve Microsoft Excel programları kullanılarak içerik analizi yöntemiyle çözümlenmiştir. Çalışmada makalelerinin çoğunluğunun Web of Science'da dizinlenen dergilerden elde edildiği; en s1k 2018 yılında yayın yapıldığı; en fazla sayıda makalenin Computers \& Education dergisinde yayınlandığı; bilgisayar destekli/web tabanlı eğitim alanında sıklıkla çalışıldığı; en sık nicel yöntemin tercih edildiği; veri toplama aracı olarak en yaygın motivasyon anketi/ölçeği veya envanterinin kullanıldığı; örneklem grubu olarak sıklıkla üniversite öğrencilerinin tercih edildiği; veri analiz tekniğinde ise en yaygın olarak t testinin kullanıldı ̆̆ı belirlenmiştir.
\end{abstract}

\begin{abstract}
In this study which aims to determine the general tendencies of the applied articles related to educational use of ARCS motivational model, document analysis method was used. In this study, 128 applied articles in journals indexed in Web of Science, ERIC, SCOPUS, ULAKBIM and Google Scholar were examined and classified by electronic form. The studies were analyzed with content analysis method using Google Forms and Microsoft Excel programs.It is determined that the majority of the articles in the study were obtained from the journals indexed in Web of Science; the largest number of publications were published in the year 2018; most articles are published in Computers \& Education; the most studied subject area is computer assisted/web based training; the most used method is quantitative method; the most common data collection tool is the motivation questionnaire; the most used sample group is university students; and the most commonly used data analysis technique is the $t$ test.
\end{abstract}

Keywords: Content analysis; ARCS model; motivation

\section{EXTENDED ABSTRACT}

\section{Introduction}

Today's educational approach aims to create an educational environment that takes the student to the center and takes into account the interests and needs of the student. Not only the cognitive and psychomotor needs of the students but also their affective needs are taken into account. Among the affective variables, students' academic self-concept, attitudes, self-confidence, anxiety, perceptions, self-esteem, the focus of control and motivation can be said (Higbee, 1999). Within these affective characteristics, the concept of motivation, which affects both the other affective features and the cognitive and dynamic processes, becomes prominent. Motivating means moving to do something (Ryan and Deci, 2000). Motivation is seen as one of the key factors that determine the direction, intensity, determination and achievement speed of student behaviors (Akbaba, 2006). In this respect, it is important to focus on motivation in learning environments. Undoubtedly, the person who makes an impression the most on the student is a teacher. Therefore, students' motivation towards their teachers should be taken into consideration.

\section{Method}

In this study, which is based on the use of the ARCS motivation model in education, content analysis was used. Cohen, Manion, and Morrison (2007) emphasized that content analysis is a repetitive, observable, systematic, and specific rule-based research technique that consists of editing, summarizing, comparing and interpreting texts. The sample of the study consists of 128 applied articles that were published on the educational use of the ARCS motivation model between 1997-2018 in journals indexed in Web of Science, Scopus, ULAKBIM, ERIC, and Google Scholar databases. The article classification form used in the study was formed by the researchers based on the research questions of the study and by using the publication

\footnotetext{
Öğretmen, Milli Eğitim Bakanlığı, Erzurum-Türkiye, vahit442@gmail.com, https://orcid.org/0000-0002-0493-2361

2 Doç, Dr., Giresun Üniversitesi, Ĕgitim Fakültesi, Bilgisayar ve Öğretim Teknolojileri Öğretmenliği Bölümü, Giresun-Türkiye, ozlem.baydas@giresun.edu.tr, https://orcid.org/0000-0002-5812-7085

Prof. Dr., Atatürk Üniversitesi, Eğitim Fakültesi, Bilgisayar ve Öğretim Teknolojileri Öğretmenliği Bölümü, Erzurum-Türkiye, yukselgoktas@atauni.edu.tr, http://orcid.org/0000-0001-5636-7352
} 
classification form of Göktaş et al. (2012). The form consists of the name of the article, author, year of publication, magazine, subject area, method, data collection tools, sample group, data analysis technique and database sections. The articles used in the research were analyzed with content analysis and the obtained data were analyzed by using Google Forms and Microsoft Excel. The data were calculated as frequency and percentage, as the answer to each research question. The generated numerical data are presented with charts or tables.

\section{Results, Discussion, and Conclusion}

It is determined that most of the articles in the study were obtained from Web of Science; the largest number of publications were published in the year 2018; the most articles are published in Computers \& Education; the most studied subject area is computer-assisted/web-based training; the most used method is quantitative method; the most common data collection tool is the motivation questionnaire/scale or inventory; the most used sample group is university students, and the most commonly used data analysis technique is the t-test. In the study, the most number of applied articles between the years of 1997-2018 is from Web of Science; the least number of articles were taken from ULAKBİM. It was seen that the largest number of publications were published in the year 2018; a small number of articles were published in the early 2000s and before 2000; especially after 2008, the interest in ARCS motivation model increased. It is thought that this depends on the importance of motivation due to changes in information technologies and the educational environment and the effectiveness of the ARCS motivation model in many studies which can be considered important. In the study, it was seen that the most number of studies were published in Computers \& Education between 1997-2018. This result was also obtained in the study of Korucu, Usta, and Atun (2017). This journal was followed by ETR\&D and IJETL journals respectively. Besides, it was seen that 73 journals contain only one article. Therefore, it is possible to say that applied articles based on the ARCS motivation model are not concentrated in certain journals. When the articles used in the study were examined, it was seen that the subject area studied the most is computer-assisted/web-based training. It was seen that the subject area of instructional models, methods or designs follows this.

According to the results of the articles included in the study, similar to the results of Kula Wassink and Sadi (2016) and Sevgi (2016), it was seen that the most number of studies conducted with quantitative research methods. In the study, the most commonly used data collection tool was identified as a motivation survey, scale or inventory developed to determine the level of motivation. Another tool used extensively for data collection is the achievement test. The learning permanence test was the least used tool. Permanence test is a test conducted after a long period of pre-test and post-test. For example, Çiftçi (2006) applied the permanence test 14 weeks after the application. Therefore, this test is thought to be preferred due to the need to spread the research over a long period. When the sample group of the studies was examined, it was seen that the sample group consisted of university students in the most number of studies. It is thought that this is preferred by the researchers due to easy accessibility (Güven, Aslan and Akyol, 2017), to be suitable for bureaucratic processes and economics. It was determined that the t-test is frequently used as data analysis technique. This result is compatible with Saracaloğlu et al. (2014). The least used data collection tools were $\mathrm{z}$ test and the PLS test. Also, it was determined that advanced statistical techniques (Mancova, etc.) are used much less. It is believed that this is because many researchers do not have the equipment to implement new and more complex statistical techniques.

\section{GİRIŞ̧}

21. yüzyılda yeni yaklaşımlar 1şığında ele alınan eğitim süreci, her yönüyle sorgulanmakta ve üst düzey düşünme becerilerinin geliştirilmesini amaçlamaktadır. Üst düzey bilişsel düşünme becerilerini geliştirmek amacıyla öğrencilerin yazmaları, tartışmaları ve problem çözme çalışmalarına katılmaları önem taşımaktadır (Svinivki \& McKeachie, 2011). Üst düzey bilişsel gelişim özelliklerini dikkate alan bu yaklaşımlar öğrencilerin ihtiyaçlarını, ilgilerini, tutum ve motivasyonel özelliklerini de dikkate alarak öğrenci merkezli öğrenmenin önemine vurgu yapmaktadır. Bu doğrultuda öğrencilerin yalnızca bilişsel ihtiyaçları değil duyuşsal ihtiyaçlarının da dikkate alındığı öğrenme ortamlarının tasarlanması ön plana çıkmaktadır. Duyuşsal değişkenler arasında öğrencilerin akademik benlik kavramları, tutumları, özgüvenleri, kaygıları, derse yönelik algıları, özsaygıları, denetim odakları ve motivasyonları gösterilebilir (Higbee, 1999). Bu duyuşsal özellikler içerisinde, hem diğer duyuşsal özellikleri hem de bilişsel ve devinimsel süreçleri etkileyen motivasyon kavramı öne çıkmaktadır.

Motive olmak (güdülenmek), bir şeyler yapmak için hareket etmek demektir (Ryan ve Deci, 2000). Yani motivasyon, bir bireyin yaptığ 1 her türlü eylemi başlatan, harekete geçiren unsur olarak görülmektedir. Bu anlamda motivasyon, eğitimsel etkinliklerin sağlıklı bir şekilde yürütülebilmesi ve her türlü istendik çıktının alınabilmesi için ön adım olarak görülebilmektedir. Zira organizmanın hedefe ulaşmasına yol 
gösteren ve enerji sağlayan güç olan motivasyon, organizmanın davranışa geçmesinde ve öğrenmesinde önemli bir role sahiptir (Yüksel, 2011). Motivasyon, öğrenci davranışlarının yönünü, şiddetini, kararlılığını ve hedeflere ulaşmadaki hızını belirleyen kilit unsurlardan biri olarak görülmektedir (Akbaba, 2006). Eğitim ortamlarında öğrenme güçlüklerinin ve istenmeyen davranışların çoğunluğu motivasyonun sağlanmamasıyla ilgilidir. Çünkü öğrenmeye karşı motive edilmemiş öğrenci için yapılan uğraşlar yetersiz kalmaktadır. Bu bağlamda öğrenme ortamlarında motivasyon kavramı üzerine odaklanma ve bu alana ilişkin model ve kuramları dikkate alma önem taşımaktadır.

Alan yazında motivasyon üzerine pek çok kuram ve model çalışmaları geliştirilmiştir. Bu çalışmalar arasında yer alan öz belirleme kuramı çerçevesinde motivasyon, içsel- dışsal motivasyon ve motivasyonsuzluk olarak sınıflandırılmaktadır. İçsel motivasyon, kişinin zevk alma, meydan okuma ve eğlence amaçlı olarak motive olmasını ifade etmektedir. İçsel motivasyonun bir örneği, çeşitli hobiler için zaman ayırma, çeşitli yarışmalara katılma veya gönüllü olarak faaliyetlere ve projelere katılma davranışıdır (Calp, 2013). İçsel motivasyon insanların zorluklarla başa çıkmalarına, kaostan düzen yaratmalarına, itici güçlerini düzenlemelerine veya ilginç faaliyetlerde bulunmalarına neden olabilir (Deci ve Ryan, 1985). Dışsal etkiler, baskılar, ödüller ve cezalar ise dışsal motivasyon kavramı kapsamında yer almaktadır (Ergin ve Karataş, 2018). Bir kişinin saygınlık kazanma isteği dışsal motivasyona örnek olarak gösterilebilir. Motivasyonsuzluk ise davranış geliştirme niyetinin olmaması, motivasyonun yokluğu, kişilerin içsel veya dışsal açıdan motive olamama durumu olarak tanımlanmaktadır (Ergin ve Karataş, 2018)

$\mathrm{Bu}$ alana ilişkin bir diğer model olan Eggen ve Kauchak'ın öğrenme odaklı sınıf modeli öğrenci güdülenmesine ilişkin öğeleri göstermekte ve güdülenmede etkili olan üç temel unsura vurgu yapmaktadır: öğretmen nitelikleri (öğretmenin tutumu, davranışları vb.), iklim değişkenleri (olumlu-olumsuz sınıf iklimi) ve öğretim değişkenleri (Bacanlı, 2009). Bu öğelere ve alt birimlere bakıldığında motivasyonun, eğitim süreçlerinde öğrenciyi etkileyen tüm değişkenlerle ilişkili olduğu görülmektedir.

Alan yazında motivasyonla ilgili bu kuram ve modellerin yanı sıra doğrudan motivasyon üzerine geliştirilmiş olan pek çok kuram ve model bulunmaktadır. Ancak bu kuramların bazıları, eğitsel açıdan yeterli uygulama alanı bulamamıştır. Bixler (2006) öğrenme ortamlarında dört motivasyonel modelin uygulama alanı bulabildiğini ve motivasyonu geliştirici etkisi olduğunu belirtmiş̧tir (Bkz. Şekil 1).

Kültürel Olarak Duyarlı Öğretme İçin Motivasyon Çerçevesi (Wlodkowski, 1999)

Öğrenme İçin İçsel Motivasyonların Taksonomisi ( Malone ve Lepper, 1988)

Zaman Sürekliliği Motivasyon Modeli (Wlodkowski, 1985)

ARCS Motivasyon Modeli (Keller, 1983)

Şekil 1. Eğitimde uygulama alanı bulan motivasyonel modeller

Kültürel olarak Duyarlı Öğretme için Motivasyon Çerçevesi Wlodkowski'nin daha önceki çalışmalarına ve öğretim sürecine kültürel duyarlılık kavramını entegre etme çabasıdır. Bu çerçevenin katılımı sağlama, tutum geliştirme, anlamı artırma ve yeteneği oluşturma olmak üzere dört temel bileşeni vardır. Modelde bu dört bileşen altında 60 motivasyon stratejisi açıklanmıştır (Bixler, 2006).

Öğrenme için İçsel Motivasyonların Taksonomisi ise bireysel ve kişilerarası içsel motivasyon üzerine geliştirilmiş bir modeldir. Bireysel motivasyon, zorluk düzeyi, merak, kontrol ve fantezi stratejilerinden; kişilerarası motivasyon, işbirliği, rekabet ve farkındalık stratejilerinden oluşmaktadır (Karsli, 2015).

Zamanın sürekliliği motivasyon modeli, motivasyonun ardışı işlem ve yöntemlerle kavramsallaştırılabileceğini ve bu şekilde öğrencinin motivasyonunun artırılabileceğini ileri sürmektedir. Model; değer, ilgi çekme, azim ve motivasyonu sürdürme olmak üzere öğretimdeki dört unsura odaklanmaktadır. Modelde, öğretim öncesinde tutum ve gereksinim; öğretim sırasında uyarılma ve etkilenme; öğretim sonrasında ise yeterlik ve pekiştirme stratejilerinin uygulanması önerilmektedir (Acar, 2009; Bixler, 2006; Karsl1, 2015). 
John M. Keller'in ARCS motivasyon modeli ise, eğitim çalışmalarında en yaygın kullanılan model olarak motivasyon kuramları arasında yer almaktadır. Temeli Victor H. Vroom'un Beklenti Değer Kuramı'na (1964) dayanmakta olup (Bixler, 2006), kuramsal yapısı Keller tarafından 1983 yılında ortaya konulmuş ve günümüze dek araştırmacının pek çok çalışmasıyla detaylandırılmış ve farklı boyutlarıyla açıklanmıştır. ARCS motivasyon modeli; öğrencilerin güdülerini harekete geçirmeyi ve sürekli kılmayı hedefleyen bir öğretim ortamında, güdüleyici yolların nasıl izleneceğini açıklamaya çalışmaktadır (Çetin, 2007). ARCS motivasyon modeli, motivasyonel kavramların ve özelliklerin; dikkat (attention), ilişki (relevance), güven (confidence) ve doyum (satisfaction) kategorilerinin sentezine dayanır. Bu dört kategori, bir kişinin tamamen motive olması için gereken koşulları temsil etmektedir. $\mathrm{Bu}$ temel unsurlar, motivasyonu temsil eden bileşenlere ve alt kategorilere ayrılmaktadır (Keller, 2000). Bu modele ilişkin bileşenler, kategoriler ve stratejiler Şekil 2'de sunulmaktadır.

Dikkat (Attention)
A1- Algısal Uyarılma
•Öğrencilerin derse
karşı ilgisini çekme

A2-Araştırmaya
Yönelik Uyarılma
•Etkinliklerle derse
yönelik merak ve
isteklerini
yönlendirme

\section{A3- Değişkenlik}

- Derse yönelik tutumlarını ve ilgilerini sürdürme

Uygunluk (Relevance)
R1- Hedefe Yöneltme
•Öğrencilerin
gereksinimlerini
karşılayıcı etkinlikler
yapılması
R2- Güdü Eşleşmesi
•Başarı için uygun
etkinlik ve ortamın
sağlanması
R3- Yakınlık-Aşinalık
•Etkinliklerin,
öğrencilerin
yaşamındaki
deneyimlerle ilişkisini
sağlama

Doyum (Satisfaction)
S1- Doğal Sonuçlar
•Öğrenciye, kazandığı
bilgileri
uygulayabileceği
ortam oluşturma
S2- Olumlu Sonuçlar
•Başarıyı arttırma ve
sürdürme için yapılan
ödüllendirme vb.
süreçleri oluşturma
S3- Eşitlik- Adalet
•Başarı için belirlenen
amaçlar ile sonuçların
uyumunun sağlanması
ve değerlendirmede
standartlaştırma

Şekil 2. ARCS motivasyon modeli ve bileşenleri (Keller, 1987a)

ARCS motivasyon modelinde; dikkat evresi, merak uyandırma, ilgi çekme ve sürdürmeye; uygunluk evresi, öğrencilerin öğrendiklerini yaşamla ilişkilendirmesine; güven evresi, başarma duygusunun geliştirilmesine; doyum evresi ise, öğrencilerin içsel bir güdülenme ve doyum kazanmasına yöneliktir (Keller, 1987b). ARCS motivasyon modeli kapsamında modelin tanıtımı ve eğitimsel açıdan farklı alanlardaki uygulamaları üzerine pek çok çalışma John M. Keller tarafindan yapılmıştır (Keller, 1979; 1983; 1987a; 1987b; 1999; 2000; 2008; 2010, 2011; Kim ve Keller, 2004; Keller ve Suzuki, 2011). Son olarak eğitim alanındaki deneysel çalışmalarda modelin kullanımına ilişkin bir alanyazın tarama çalışması yapılmıştır (Li ve Keller, 2018). Ayrıca alan yazındaki çalışmalar incelendiğinde, ARCS motivasyon modelinin belli bir alana veya derse yönelik tutuma, öğrenci motivasyonuna, ilgiye, öğrenmenin kalıcılığına, öz yeterliliğe etkisinin yanı sıra akademik başarıya etkisi üzerine de pek çok çalışma (tez, makale ve bildiri) yapıldığı görülmektedir. Eğitim alanında yapılan bir çok çalışmada ARCS motivasyon modelinin akademik başarıyı artırdığı belirlenmiştir (Aşıksoy ve Özdamlı, 2016; Ergin ve Karataş, 2018; Karakış, Karamete ve Okçu, 2016; Thaer ve Thaer, 2016). ARCS motivasyon modelinin bu başarılı etkisi ilk ve ortaöğretim ortamlarının yanı sıra pek çok farklı ortamlarda yürütülen çalışmalarda da ortaya konulmuştur. Zhang'ın (2017) çalışmasında ARCS motivasyon modeli'nin mühendislik uygulamalarında kullanımının; Means, Jonassen ve Dwyer'ın (1997) çalışmasında ise sağlık bilimleri alanında kullanımının başarıya olumlu etkisi olduğu belirlenmiştir. Birçok çalışmada öğrencilerin derse karşı tutumlarına olumlu etkisinin olduğu (Balantekin,2014; Balantekin ve Bilgin, 2017; Karsl1, 2015), öğrenme motivasyonlarına olumlu etki yaptığı (Aşıksoy ve Özdaml1, 2016; Su ve Cheng, 2013), derslerde öğrenmenin kalıcılığını artırdığı ortaya çıkarılmıştır (Cengiz, 2009; Cengiz ve Aslan, 2012). Bazı çalışmalarda ise ARCS motivasyon modeli temel alınarak geliştirilmiş materyallerin öğrencilerin öz yeterlilik algılarına olumlu etki ettiği (Aslan, Şılbır ve Karaman, 2016), geliştirilen öğretim tasarımlarının ya da öğretim materyallerin 
eğitimsel anlamda başarılı olduğu ve öğrencilerin başarısını ve çeşitli duyuşsal değişkenleri olumlu yönde etkilediği görülmüştür (Bolliger, Supanakorn ve Boggs, 2010; Ono ve Ishihara, 2012; Su ve Cheng, 2013). Huang, Huang ve $\mathrm{Wu}$ (2014)'ün çalışmasında da bu model temel alınarak kurgulanan bir öğretim uygulamasının öğrencilerin kaygılarını azalttı̆̆ı, buna bağlı olarak öğrenme motivasyonlarını ve öğrenme performanslarını arttırdığı sonucuna ulaşılmıştır. Görüldüğg̈ üzere ARCS modeli birçok araştırmanın kapsamında yer almış ve bu model ile genellikle olumlu sonuçlar elde edilmiştir.

ARCS motivasyon modelinin uzun yıllardır alan yazında sıklıkla kullanılması, eğitim çalışmalarındaki yerinin daha detaylı olarak incelenmesi ihtiyacını ortaya koymaktadır. Özellikle çeşitli konu alanlarında yürütülen çalışmalar düşünüldüğünde bu araştırmaların eğilimlerinin çeşitli değişkenler açısından incelenmesi, araştırmacıların bu alandaki gelecek çalışmalarına yön verebilir. Model üzerine yeterince çalışma yapılmış alanların ortaya çıkarılması, gelecek araştırmalara yönelik ihtiyaç duyulan çalışma alanlarının belirlenmesine katkı sunacaktır. Yöntemsel olarak elde edilen veriler de gelecek çalışmaların desenlenmesinde ve çalışma süreçlerinin planlanmasında yol gösterici olması açısından önemlidir. Hangi örneklemin sıklıkla seçildiğini, hangi veri toplama aracının ve analiz tekniğinin sıklıkla kullanıldığını ortaya çıkarmak, gelecek araştırmaların tasarlanmasında benzer uygulamaların yürütülerek genelllemelerin yapılabilmesine ve alandaki boşluğun tespit edilerek farklı uygulamalar geliştirilebilmesine yardımcı olabilir. Bu nedenlerle, 1997-2018 yılları arasında ARCS motivasyon modelinin eğitimde kullanımını temel alan ulusal ve uluslararası yayınlanmış uygulamalı makale çalışmalarının incelendiği bu araştırmada, incelenen makalelerin hem yöntemsel hem de içeriksel boyutuna ilişkin genel eğilimlerin belirlenmesi amaçlanmaktadır. $\mathrm{Bu}$ amaç doğrultusunda aşağıdaki sorulara cevap aranmaktadır: ARCS motivasyon modelini temel alan uygulamalı eğitim makalelerinin;

1. Elde edildikleri veri tabanlarına göre dağılımı nedir?

2. Yayınlandıkları yıllara göre dağılımları nasıldır?

3. Siklıkla yayınlandığı dergiler hangileridir?

4. Sıklıkla çalışılan konu alanları nelerdir?

5. Sıklıkla kullanılan araştırma yöntemleri nelerdir?

6. S1klıkla kullanılan veri toplama araçları nelerdir?

7. Hangi örneklem grupları ile çalışılmıştır?

8. Sıklıkla kullanılan veri analiz teknikleri nelerdir?

\section{YÖNTEM}

ARCS motivasyon modelinin eğitimde kullanımını temel alan uygulamalı makale çalışmalarının incelendiği bu araştırma doküman analizi ile yürütülmüştür. Döküman analizi, basılı ve elektronik (bilgisayar tabanlı ve Internet üzerinden iletilen) materyalleri incelemek veya değerlendirmek için kullanılan sistematik bir yöntemdir (Bowen, 2009). Bu süreç içerik analizi yardımıyla gerçekleştirilmiştir. Cohen, Manion ve Morrison (2007) içerik analizinin; metinlerin düzenlenmesi, özetlenmesi, karşılaştırılması ve yorumlanmasından oluşan; tekrarlanabilir, gözlemlenebilir, sistematik ve belli bir kurala dayanan bir araştırma tekniği olduğunu vurgulamışlardır. İçerik analizinde yapılan temel iş, benzer verileri belirli kavramlar çerçevesinde toparlamak ve anlaşılır bir biçimde yorumlamaktır (Yıldırım ve Şimşek, 2016). Çalışmada, ARCS motivasyon modelini temel alan ulusal ve uluslararası yayınlanmış uygulamalı makale çalışmaları, belirli kodlar ve kategoriler çerçevesinde incelendiğinden içerik analizi yöntemi kullanılmıştır.

\subsection{Araştırmanın Kapsamı}

Araştırmanın evreni, ARCS motivasyon modelini temel alan tüm çalışmalardan oluşmaktadır. Araştırmanın örneklemi ise Web of Science, Scopus, ULAKBIM, ERIC ve Google Scholar veri tabanlarında taranan dergilerde, 1997-2018 yılları arasında ARCS motivasyon modelinin eğitsel kullanımı üzerine yayınlanmış 128 uygulamalı makaleden oluşmaktadır. ARCS motivasyon modeline yönelik 1997 yılından itibaren uygulamalı çalışmalara sıklıkla ulaşılması, araştırma kapsamında belirtilen yılın referans alınmasını sağlamıştır. Öncelikli olarak araştırmacılar tarafindan Web of Science'de SSCI ve SCI indeksli ARCS motivasyon modeli alanında yayınlanan makaleler belirlenmiş $(\mathrm{n}=50)$, daha sonra sınırlılıklar çerçevesinde yeterli çalışma bulunamadığından diğer veritabanları ERIC $(n=18)$, SCOPUS $(n=16)$, ULAKBİM $(\mathrm{n}=15)$ ve son olarak Google Scholar'dan $(\mathrm{n}=29)$ ulaşılan makaleler tespit edilmiştir. Araştırmalarda anahtar kavram olarak ARCS motivasyon modeli, ARCS model, motivasyon, motivation, motivational model, motivation theory kavramları kullanılmıştır. Birden fazla veritabanından elde edilen 
aynı makaleler ayıklanmıştır. Araştırmaya dahil edilen makaleler ek kaynakçada sunulmuştur. Makalelerin belirlenmesinde aşağıdaki ölçütler dikkate alınmıştır:

- $\quad$ ARCS motivasyon modelini temel almasi,

- $\quad$ Eğitim alanında veya eğitimsel amaçla yapılmış olması,

- $\quad$ Makale türünde olmasi,

- WOS (SSCI, SCI, ESCI), ULAKBIM, ERIC, SCOPUS veya Google Scholar'dan alınmış olması,

- $\quad$ 1997- 2018 yılları arasında yapılmış olması,

- $\quad$ Nicel, nitel veya karma yöntemle yapılmış olması (derleme, görüş makaleleri dahil edilmemiştir).

\subsection{Veri Toplama Süreci}

Çalışmada kullanılan makale sınıflama formu çalışmanın araştırma sorularına dayanarak ve Göktaş vd.(2012)'nin yayın sınıflama formundan yararlanılarak, araştırmacılar tarafından oluşturulmuştur. Geliştirme sürecinde öncelikle Microsoft Excel ortamında taslak form oluşturulmuş, ardından bu form üzerinde araştırmacılar ve akran görüşleri alınarak gerekli düzenlemeler yapılmıştır. Bu görüşler çerçevesinde son kez düzeltilen ve veri toplama aracı olarak kullanılan form, 10 sorudan oluşmaktadır. $\mathrm{Bu}$ sorular makalenin künyesine ve araştırma sorularında elde edilmek istenen bilgilere ilişkindir. Form; makalenin adı, yazarı, yayın yılı, dergisi, konu alanı, yöntemi, veri toplama aracı, örneklem grubu, veri analiz tekniği ve alındığı veritabanı bölümlerinden oluşmaktadır. Elde edilen veriler, araştırma sorusunda istenen bilgi temel alınarak doldurulmuştur. Dergi, konu alanı ve araştırma yöntemi tek bir seçenekten oluştuğundan çoktan seçmeli olarak kodlanmış; veri toplama aracı, örneklem grubu, veri analiz tekniği birden fazla olabildiği için çoklu seçim yapılarak kodlanmıştır. Bazı makalelerin birden fazla veritabanında taranabildiği görülmüş ancak indeksli dergilerin yer aldığı veritabanları öncelikli olarak taranmıştır. Web of science, SCOPUS ve ERIC, öncelikli olarak dikkate alınmıştır. Ulusal veritabanı olan ULAKBİM ile Google scholar ise ikincil olarak taranmıştır. Bu açıdan makalelerin hangi platformda yer aldığını göstermek adına veritabanı için tek bir seçenek kodlanmıştır.

\subsection{Verilerin Analizi}

Araştırmada kullanılan makaleler, içerik analiziyle incelenmiş ve elde edilen veriler Google Formlar ve Microsoft Excel programları kullanılarak betimsel istatistiki tekniklerle çözümlenmiştir. Veriler, her bir araştırma sorusunun yanıtı olacak şekilde frekans ve yüzde olarak hesaplanmıştır. Oluşturulan sayısal veriler, çizelge veya grafiklerle sunulmuştur.

\subsection{Geçerlik ve Güvenirlik}

Araştırmada geçerlik ve güvenirliğin sağlanması kapsamında pek çok çalışma yapılmıştır. Araştırmaya kaynak olan makaleler ayrıntılı bir şekilde kaynakçada belirtilmiştir. Veri toplama ve analiz süreci açıkça belirtilmiştir. Ayrıca verilerin doğruluğundan emin olmak için makalelerin tabloya doldurulması iki aşamada gerçekleştirilmiştir. Son olarak da veriler, araştırmacı tarafından incelenmiş ve gerekli düzenlemeler yapılmıştır.

\section{BULGULAR}

1997-2018 yılları arasında yayımlanmış 128 makaleye ilişkin veriler, Excel ortamında oluşturulan makale sınıflama formu kullanılarak ve araştırmanın soruları dikkate alınarak çözümlenmiştir. Elde edilen bulgular araştırmanın sorularına dayandırılarak aşağıda sunulmuştur.

\subsection{ARCS Motivasyon Modelini Temel Alan Uygulamalı Makalelere Ulaşılan Veritabanları}

Araştırmada analizi yapılacak olan makaleler farklı veritabanlarından elde edilmiştir. Çalışmada veritabanlarında yer alan makalelerde Web of Science $(n=50)$ ilk sırada yer almaktadır. ULAKBİM $(n=15)$ ise en az makalenin yer aldığı veritabanıdır. Çalışmada yer alan makalelerin veritabanlarına göre dağılımı Şekil 3'de verilmiştir. 


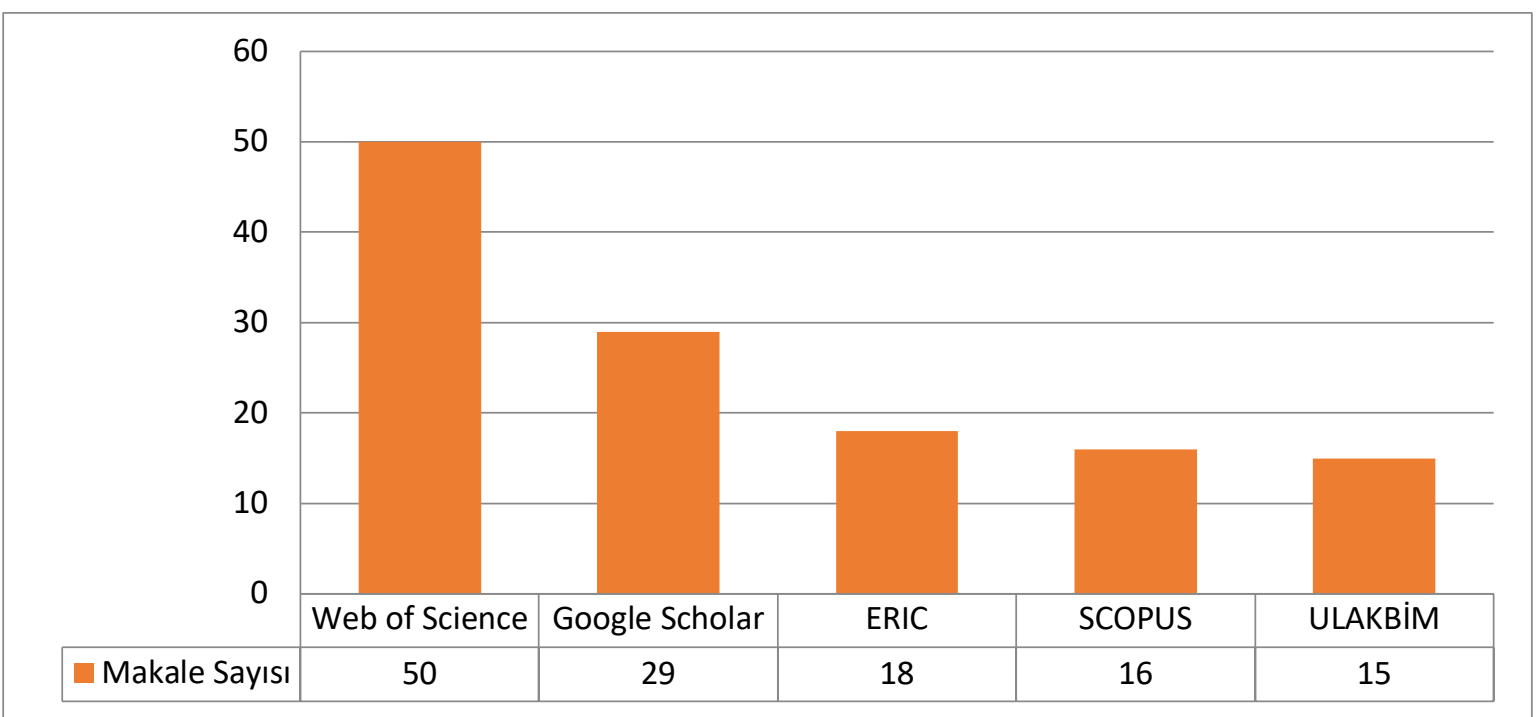

Şekil 3. ARCS motivasyon modelini temel alan uygulamalı makalelerin veritabanları

\subsection{ARCS Motivasyon Modelini Temel Alan Uygulamalı Makalelerin Yayınlandığı Yıllar}

ARCS motivasyon modeli temel alınarak yürütülen makalelerin en sik 2018 y1lında $(n=28)$ yayınlandığı görülmektedir. Ayrıca sirasıyla 2015 (n=17), 2016 ve $2017(\mathrm{n}=15)$ yıllarında siklıkla makalelerin yayınlandığı ortaya çıkarılmıştır. En az yayın yapılan yılların ise, 1997, 2001, 2002, 2003, 2005 $(n=1)$ olduğu görülmektedir. Makalelerin yayınlandıkları yıllara göre dağılımı Şekil 4'te sunulmuştur.

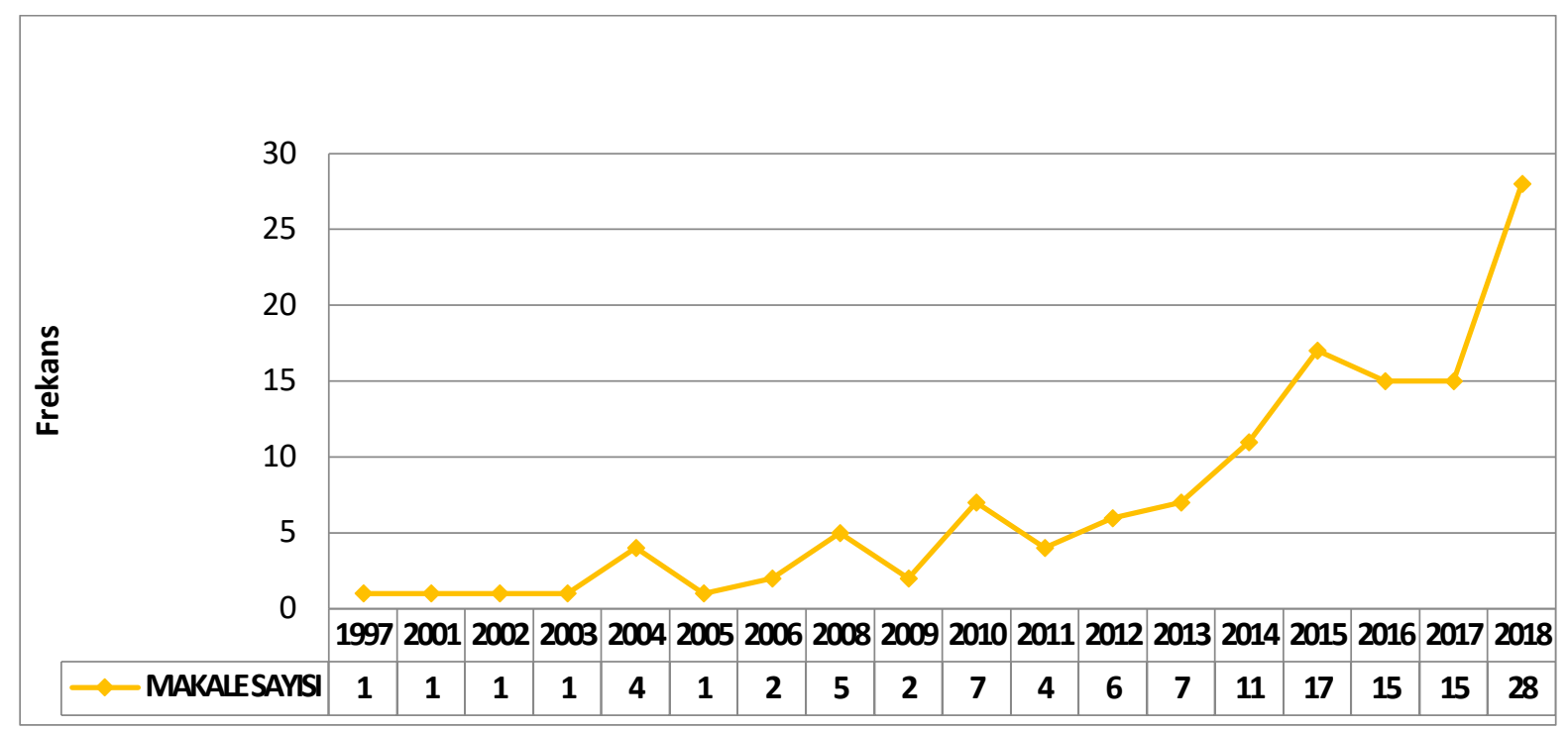

Şekil 4. ARCS motivasyon modelini temel alan uygulamalı makalelerin yayın yılları

\subsection{ARCS Motivasyon Modelini Temel Alan Uygulamalı Makalelerin Yayınlandığı Dergiler}

Araştırmada analiz edilen makalelerin 88 farklı dergide yayımlandıkları görülmüştür. ARCS motivasyon modeli temel alınarak yapılmış olan eğitsel araştırmaların en yoğun olduğu derginin Computers \& Education ( $\mathrm{n}=10)$ olduğu görülmektedir. Dergilerin büyük çoğunluğunun ( 73 derginin) yalnızca birer makale içerdiği de elde edilmiş̧ir. En fazla sayıda çalışmanın yayımlandığı dergilerin dağılımı Tablo 1'de verilmiştir.

Tablo 1. ARCS motivasyon modelini temel alan makalelerin en çok yayımlandığı dergiler

\begin{tabular}{|l|c|}
\hline \multicolumn{1}{|c|}{ Dergi Adı } & f \\
\hline Computers \& Education & 10 \\
\hline Educational Technology Research \& Development & 5 \\
\hline International Journal of Emerging Technologies in Learning & 4 \\
\hline
\end{tabular}




\begin{tabular}{|l|c|}
\hline Interactive Learning Environments & 4 \\
\hline Eurasia Journal of Mathematics, Science \& Technology Education & 3 \\
\hline British Journal of Educational Technology & 3 \\
\hline Turkish Online Journal of Distance Education & 3 \\
\hline Journal of Computer Assisted Learning & 3 \\
\hline Ahi Evran Üniversitesi Kirşehir Eğitim Fakültesi Dergisi & 2 \\
\hline College \& Research Libraries & 2 \\
\hline Elementary Education Online & 2 \\
\hline European Journal of Contemporary Education & 2 \\
\hline Innovations in Education and Teaching International & 2 \\
\hline International Forum of Educational Technology \& Society & 2 \\
\hline Kastamonu Eğitim Dergisi & 2 \\
\hline Journal of Instructional Technologies \& Teacher Education & 2 \\
\hline Journal of Education and Future & 2 \\
\hline International Journal of Instruction & 2 \\
\hline
\end{tabular}

\subsection{ARCS Motivasyon Modelini Temel Alan Uygulamalı Makalelerin Konu Alanları}

ARCS motivasyon modelini temel alan uygulamalı makalelerde sıklıkla bilgisayar destekli/web tabanlı eğitim $(\mathrm{n}=34)$ ve ögretim model, yöntem ve tasarımları $(\mathrm{n}=22)$ konu alanları üzerine uygulamalar yürütülmüştür. Özel eğitim, kütüphane eğitimi, mesleki ve teknik eğitim, yetişkin eğitimi ile beden eğitimi ve spor $(\mathrm{n}=1)$ konu alanlarında ise en az sayıda çalışmanın olduğu görülmektedir. Bu çalışmaların konu alanlarına göre dağılımı Tablo 2'de sunulmuştur.

Tablo 2. ARCS motivasyon modelini temel alan uygulamalı makalelerin konu alanları

\begin{tabular}{|c|c|}
\hline Konu Alanı & $\mathbf{f}$ \\
\hline Bilgisayar destekli/Web tabanlı eğitim & 34 \\
\hline Öğretim Model, Yöntem ve Tasarımları & 22 \\
\hline Dil Eğitimi & 15 \\
\hline Mobil Öğrenme & 10 \\
\hline Matematik Eğitimi & 9 \\
\hline Sanal Dünyalar & 6 \\
\hline Mühendislik Eğitimi & 6 \\
\hline Ölçek Geliştirme & 5 \\
\hline Fen Bilimleri Eğitimi & 5 \\
\hline Bilgi Okuryazarlı̆̆ & 3 \\
\hline Açık/Uzaktan Öğretim & 3 \\
\hline Sağlık Bilimleri & 3 \\
\hline Sosyal Bilgiler eğitimi & 2 \\
\hline Beden Eğitimi ve Spor & 1 \\
\hline Kütüphane Eğitimi & 1 \\
\hline Mesleki ve Teknik Eğitim & 1 \\
\hline Özel Eğitim & 1 \\
\hline Yetişkin Eğitimi & 1 \\
\hline
\end{tabular}




\subsection{ARCS Motivasyon Modelini Temel Alan Uygulamalı Makalelerin Araştırma Yöntemleri}

ARCS motivasyon modelini temel alan uygulamalı makalelerde sıklıkla nicel araştırma yöntemlerinin kullanıldığı $(n=89)$ görülmektedir. Karma $(n=17)$ ve nitel $(n=22)$ araştırma yöntemleriyle benzer sıklıkta araştırmaların tasarlandığı görülmektedir. Bu çalışmaların araştırma yöntemlerine göre dağılımı Şekil 5'de sunulmuştur.

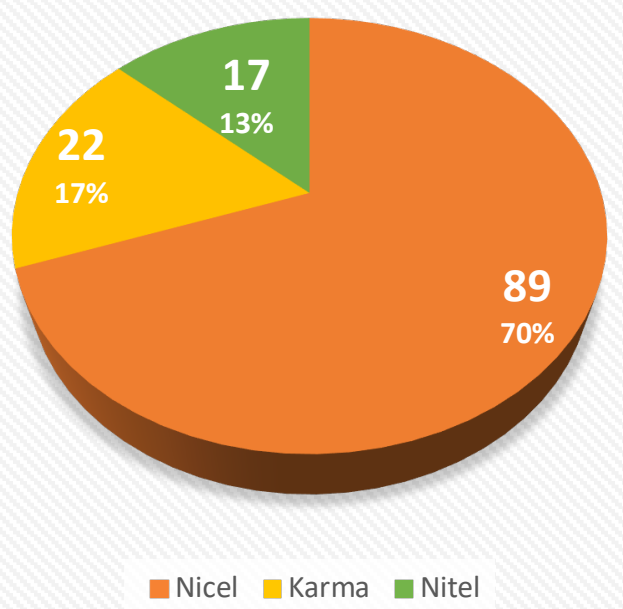

Şekil 5. ARCS motivasyon modelini temel alan uygulamalı makalelerin yöntemleri

\subsection{ARCS Motivasyon Modelini Temel Alan Uygulamalı Makalelerin Veri Toplama Araçları}

ARCS motivasyon modelini temel alan uygulamalı makalelerde pek çok farklı veri toplama aracının kullanıldığı görülmüştür. En sık kullanılan veri toplama aracının motivasyon düzeyini ölçmeye yönelik ölçek, anket veya envanterler $(n=99)$ olduğu, ayrıca başarı testinin $(n=52)$ de yoğun olarak kullanıldığı belirlenmiştir. Kalıcılık testinin $(n=2)$ ise en az tercih edildiği belirlenmiştir. Bu araçların dağglımı Tablo 3'de sunulmuştur:

Tablo 3. ARCS motivasyon modelini temel alan makalelerde kullanılan veri toplama araçları

\begin{tabular}{|l|l|l|}
\hline \multicolumn{1}{c}{ Veri Toplama Aracı } & F & Yüzde (\%) \\
\hline Motivasyon Ölçeği/Anketi/Envanteri & 99 & 40,2 \\
\hline Başarı/ Erişi Testi & 52 & 21,1 \\
\hline Görüşme Formu & 21 & 8,5 \\
\hline Diğer (Ölçek, İndeks, Envanter, Form) & 15 & 6,1 \\
\hline Gözlem Formu & 10 & 4,1 \\
\hline Açık Uçlu Sorular (Anket) & 9 & 3,7 \\
\hline İlgi Ölçeği & 8 & 3,3 \\
\hline Tutum Ölçeği & 7 & 2,8 \\
\hline Alternatif Testler & 7 & 2,8 \\
\hline Öz Yeterlilik Ölçeği & 6 & 2,4 \\
\hline Anket-Diğer (Likert) & 5 & 2,0 \\
\hline Yetenek-Beceri-Performans Testi & 5 & 2,0 \\
\hline Kalıcılık Testi & 2 & 1,0 \\
\hline
\end{tabular}

\subsection{ARCS Motivasyon Modelini Temel Alan Uygulamalı Makalelerin Örneklem Grupları}

ARCS motivasyon modelini temel alan uygulamalı makalelerde, örneklem grubunun sıklıkla üniversite öğrencilerinden $(n=70)$ oluştuğu görülmektedir. Sirasıyla ortaokul öğrencileri $(n=20)$, lise 
öğrencileri ( $\mathrm{n}=15)$ ve ilkokul öğrencileri $(\mathrm{n}=12)$ uygulamaların yürütüldüğg̈ örneklem grupları arasında yer almaktadır. Akademisyenlerin, işitme engelli öğrencilerin, kurum personellerinin, açık ve uzaktan öğretim öğrencileri ile mesleki ve teknik okul öğrencilerinin $(n=1)$ az sayıda çalışmada örneklem grubununu oluşturduğu görülmektedir. Çalışmaların örneklem gruplarının dağılımı Tablo 4 'te sunulmuştur:

Tablo 4. ARCS motivasyon modelini temel alan uygulamalı makalelerin örneklemleri

\begin{tabular}{|l|c|c|}
\hline \multicolumn{1}{|c|}{ Örneklem Grubu } & F & Yüzde (\%) \\
\hline Üniversite öğrencileri & 70 & 51,5 \\
\hline Ortaokul öğrencileri & 20 & 14,7 \\
\hline Lise öğrencileri & 15 & 11,0 \\
\hline İlkokul öğrencileri & 12 & 8,8 \\
\hline Yüksekokul öğrencileri & 4 & 2,9 \\
\hline Öğretmenler & 3 & 2,2 \\
\hline Lisansüstü öğrencileri & 3 & 2,2 \\
\hline Yaşlı insanlar & 2 & 1,6 \\
\hline Yetişkin öğrenciler & 2 & 1,6 \\
\hline Açı/Uzaktan Öğretim Öğrencileri & 1 & 0,7 \\
\hline Akademisyenler & 1 & 0,7 \\
\hline İşitme engelli öğrenciler & 1 & 0,7 \\
\hline Kurum personelleri & 1 & 0,7 \\
\hline Mesleki ve Teknik Okul Öğrencileri & 1 & 0,7 \\
\hline
\end{tabular}

\subsection{ARCS Motivasyon Modelini Temel Alan Uygulamalı Makalelerin Veri Analiz Teknikleri}

ARCS motivasyon modeli temel alan uygulamalı makalelerde, veri analiz tekniği olarak nicel tekniklerin $(\mathrm{n}=219)$ nitel tekniklere $(\mathrm{n}=33)$ göre siklıkla tercih edildiği görülmüştür. En fazla kullanılan veri analiz tekniği $t$ testi $(\mathrm{n}=53)$ iken en az kullanılanlar $z$ testi ve PLS testidir $(\mathrm{n}=2)$. Nitel veri analiz tekniklerinden ise betimsel analiz $(n=19)$, içerik analizine $(n=14)$ oranla daha fazla kullanılmıştır. Analizi yapılan makalelerde kullanılan veri analiz tekniklerinin dağılımı Tablo 5'de verilmiştir.

Tablo 5. ARCS motivasyon modelini temel alan uygulamalı makalelerin veri analiz teknikleri

\begin{tabular}{|c|c|c|c|}
\hline Veri Analiz Yöntemi & Veri Analiz Tekniği & $\mathbf{F}$ & Yüzde (\%) \\
\hline \multirow{16}{*}{ NICEL } & $\mathrm{t}$ testi & 54 & 24,7 \\
\hline & Betimsel İstatistikler & 50 & 22,8 \\
\hline & ANOVA & 29 & 13,2 \\
\hline & Korelasyon & 21 & 9,6 \\
\hline & ANCOVA & 15 & 6,8 \\
\hline & Regresyon & 9 & 4,1 \\
\hline & MANOVA & 9 & 4,1 \\
\hline & Mann Whitney U Testi & 6 & 2,7 \\
\hline & Faktör Analizi & 5 & 2,3 \\
\hline & Wilcoxon Testi & 5 & 2,3 \\
\hline & Ki-Kare Testi & 5 & 2,3 \\
\hline & MANCOVA & 4 & 1,8 \\
\hline & Kruskal Wallis Testi & 3 & 1,5 \\
\hline & Z Testi & 2 & 0,9 \\
\hline & PLS & 2 & 0,9 \\
\hline & TOPLAM & 219 & 100 \\
\hline
\end{tabular}




\begin{tabular}{|l|l|l|l|}
\hline \multirow{2}{*}{ NiTEL } & Betimsel Analiz & 19 & 57,5 \\
\hline & İçerik Analizi & 14 & 42,5 \\
\hline & TOPLAM & $\mathbf{3 3}$ & $\mathbf{1 0 0}$ \\
\hline
\end{tabular}

\section{SONUÇ VE TARTISSMA}

$\mathrm{Bu}$ çalışmada, Web of Science, ERIC, SCOPUS, ULAKBİM ve Google Scholar'da taranan ve önemli bir çoğunluğu SSCI-SCI indeksli dergilerde yer alan, 1997-2018 yılları arasında yayımlanmış 128 nitel, nicel veya karma yöntemle yapılmış makale incelenmiştir. Bu makaleler tarandığı veritabanı, yayınlandığ 1 yıllar, yayınlandığı dergiler, uygulamaların yapıldığı konu alanları, araştırma yöntemleri, veri toplama araçları, örneklem grupları ve veri analiz tekniklerine göre içerik analizi yardımıyla incelenmiştir. Çalışmada modelin eğitim öğretim sürecindeki uygulamaları incelendiğinden, kuramsal derleme ve değerlendirme makaleleri dahil edilmemiştir.

Çalışmada, 1997-2018 yılları arasında en çok sayıda uygulamalı makaleye Web of Science'den; en az sayıda makaleye ise ULAKBİM'den ulaşıldığı görülmektedir. Dünya geneli yayınlar incelendiğinde genel olarak SCOPUS'un daha fazla dergi indekslediği görülmektedir. Türkiye'de yapılan yayınlar açısından ise sosyal bilimlerde SCOPUS'un, sanat ve beşeri bilimlerde Web of Science'in (WOS) yayın sayısının fazla olduğu dikkat çekmektedir (Karasözen, Bayram ve Zan, 2011). Dolayısıyla, bu çalışmada ARCS motivasyon modeline ilişkin elde edilen yayınların önemli bir çoğunluğunun WOS'tan elde edilmesi ile genel durumun ters yönde bir eğilimde olduğu düşünülebilir.

Çalışmada analiz edilen makalelerin en fazla yayınlandığı yılın 2018 olduğu ve bunu sırasıyla 2015, 2016 ve 2017 yıllarının takip ettiği; 2000'li yılların öncesinde ve başlarında ise az sayıda makalenin yayınlandığı, özellikle 2008 yılı sonrasında ARCS motivasyon modeline ilginin arttığı görülmektedir. Bunun bilgi teknolojilerinde ve eğitim ortamındaki değişimlere bağlı olarak motivasyonun önem kazanmasına ve ARCS motivasyon modelinin etkililiğinin önemli sayılabilecek pek çok çalışmada ispatlanmasına bağlı olduğu düşünülmektedir. Dolayısıyla bu modele giderek ilginin arttığı ve gelecekte de modelin uygulanması üzerine pek çok farklı çalışmanın yapılabileceği söylenebilir.

Çalı̧̧mada, 1997-2018 yılları arasında en fazla sayıda çalışmanın Computers \& Education dergisinde yayımlandığı görülmüştür. Bu sonuç Korucu, Usta ve Atun (2017)'un çalışmasında da elde edilmiştir. Bu dergiyi sırasıyla ETR\&D ve IJETL dergilerinin izlediği görülmüşsür. Bu veriler, bu alanla ilgili çalışma yapacak olan araştırmacılar için tercih edilebilecek dergilerin belirlenmesinde yardımcı olabilir. Ayrıca 73 derginin yalnızca birer makale içerdiği görülmektedir. Dolayısıyla ARCS motivasyon modelini temel alan uygulamalı makalelerin belli dergilerde yoğunlaşmadığ 1 söylenebilir. Bu dağılım, ARCS motivasyon modeline ilişkin çalışmaların çok farklı alanlarda ve çok sayıda ülkede yapılması, dolayısıyla alana hitap eden çok sayıda derginin bulunmasından kaynaklanmış olabilir.

Çalışmada, yararlanılan makaleler incelendiğinde en fazla üzerinde çalışılan konu alanının bilgisayar destekli/web tabanlı eğitim olduğu, bunu öğretim model, yöntem veya tasarımlarının ARCS motivasyon modeliyle birlikte kullanımı ve etkililiği üzerine yapılan çalışmaların izlediği görülmektedir. Genel olarak bakıldığında, teknolojiyle ilgili alanlarda (bilgisayar-web tabanlı eğitim, mobil öğrenme, sanal dünyalar vb.) bu model üzerine çok sayıda çalışmanın olduğu görülmektedir. Teknolojik alanlara (BDE, WTE vb.) dayalı yapılan öğretimsel tasarımların öğrencilerin akademik başarısını (Demircioğlu ve Geban, 1996; Güven ve Sülün, 2012; Zheng, 2016); motivasyon düzeyini ve motivasyonel özelliklerini (Ersoy, Duman ve Öncü, 2016; Song, Kalet and Plass, 2016) artırdığ1 görülmektedir. Dolayısıyla eğitimde motivasyon üzerine çalışan araştırmacıların bu alanlara ilgili olması beklenen bir durumdur.

Çalışmaya dahil edilen makalelerin yöntemlerine bakıldığında, Kula Wassink ve Sadi (2016)'nın ve Sevgi (2016)'nın sonuçlarına benzer şekilde, sıklıkla nicel araştırma yöntemleri ile yapılmış çalışmanın olduğu görülmektedir. Karma ve nitel araştırmaların birbirine yakın sayıda ve nicel araştırmalara göre oldukça az sayıda olduğu görülmüş̧ür. Çalışmada, özellikle sınıf ortamında yapılan ve ARCS motivasyon modeli temel alınarak geliştirilen materyallerle ve öğretim tasarımlarıyla yapılan yarı deneysel çalışmaların çok sayıda ve birbirine benzer şekillerde yapıldığı görülmüştür.

Çalışmalarda, araştırmanın amacına ve yöntemine bağlı olarak kullanılan pek çok veri toplama aracı olduğu, çalışmaların önemli bir kısmında birden fazla veri toplama aracı kullanıldığı görülmüştür. En yaygın kullanılan aracın, motivasyon düzeyini belirlemeye yönelik geliştirilen motivasyon anketi, ölçeği veya envanteri olduğu belirlenmiştir. Bu araçların bir bölümünün Keller (1987c)'nin geliştirdiği Instructional Materials Motivation Survey (IMMS) veya bu anket temel alınarak geliştirilmiş versiyonları olduğu görülmüştür. Veri toplama amacıyla yoğun olarak kullanılan bir diğer araç başarı testidir. Pek çok alanda özellikle yarı deneysel çalışmalarda ön test-son test şeklinde kullanıldığı görülmüştür. Bu sonuçlar, Saracaloğlu vd. (2014)'ün çalışmasıyla da uyumluluk göstermektedir. Bu iki aracı, özellikle nitel veya 
karma çalışmalarda kullanılan görüşme formu izlemiştir. Öğrenme kalıcılığı testinin ise en az sayıda kullanılan araç olduğu görülmüştür. Kalıcılık testi, ön test-son test uygulamalarından uzun bir süre sonra uygulanan testlerdir. Örneğin Çiftçi (2006), uygulamadan 14 hafta sonra kalıcılık testini uygulamıştır. Dolayısıyla bu testin, araştırmaların uzun bir süreye yayılmasını gerektirmesinden dolayı az tercih edildiği düşünülmektedir.

Çalışmaya dahil edilen araştırmaların örneklem grubu incelendiğinde, en fazla sayıda çalışmada örneklem grubunun üniversite öğrencilerinden oluştuğu görülmüsstür. Bunun, kolay ulaşılabilirlik (Güven, Aslan ve Akyol, 2017), bürokratik işleyiş ve ekonomiklik açısından uygun olduğu için araştırmacılar tarafından tercih edildiği düşünülmektedir. Üniversite öğrencilerini, ortaokul, lise ve ilkokul öğrencileri izlemektedir. Dolayısıyla örneklemin büyük çoğunluğunun, örgün eğitim kurumu öğrencilerinden oluştuğu görülmektedir. Göktaş vd. (2012) çalışmasında, örneklem grubunun en fazla üniversite öğrencilerinden oluştuğunu belirlemiş olup, bu araştırmanın sonuçlarıyla benzerlik gösterdiği görülmektedir. Araştırma yöntemlerine bakıldığında çoğunlukla nicel araştırma -özellikle de yarı deneysel araştırma- yapılmasıyla örneklem seçiminin aynı doğrultuda olduğu söylenebilir. Çünkü araştırma yönteminin uygulanabileceği örneklem grubunun, yönteme uygun olması önemlidir. Zira en az kullanılan örneklem grubunun kurum personelleri gibi sürekli etkileşim halinde olunamayan kişiler olduğu görülmektedir.

Çalışma kapsamındaki araştırmalarda kullanılan veri analiz teknikleri incelendiğinde, çok sayıda tekniğin kullanıldığı görülmüştür. Veri analiz tekniği olarak sıklıkla t testinin kullanıldığı belirlenmiştir. Bu sonuç Saracaloğlu vd. (2014)'ün çalışmasıyla da uyumludur. En az kullanılan veri toplama araçlarının ise $\mathrm{z}$ testi ve PLS testi olduğu görülmüştür. Nitel veri analiz tekniklerinden ise betimsel analizin içerik analizine göre daha fazla sayıda kullanıldığı ortaya çıkarılmıştır. Ayrıca genel olarak, basit istatistiki tekniklerin ağırlıklı olarak kullanıldığı, ileri istatistiki tekniklerin (Mancova vb.) çok daha az sayıda kullanıldığ1 belirlenmiştir. Bunun, birçok araştırmacının yeni ve daha karmaşık istatistikî teknikleri uygulayabilecek donanıma sahip olmamasından kaynaklandığı düşünülmektedir.

\section{1.Öneriler}

ARCS motivasyon modelinin eğitimsel kullanımına ilişkin olarak yürütülen uygulamalı makalelerin genel eğilimleri belirlenmiş olup, bu doğrultuda gelecek araştırmalara yönelik birtakım önerilerde bulunulabilir. Gelecekte yapılacak olan çalışmalarda;

- S1kça çalışılmamış olan ders ve konu alanlarına ağırlık verilebilir.

- Az sayıda yapıldığı görülen nitel ve karma desenli çalışmalara ağırlık verilebilir.

- S1kça çalışılmamış olan örneklem gruplarıyla çalışmalar yapılabilir.

- Daha kapsamlı sonuçlar elde edilebilecek ileri istatistikî teknikler kullanılabilir.

- S1kça kullanılmamış olan ölçme araçlarından veya alternatif araçlardan yararlanılabilir.

Ayrıca çalışmada, bu model üzerine çok sayıda çalışma yapıldığı görülmüş olup, yıllara göre çalışma sayısının sürekli artış gösterdiği ve bu artışın gelecek yıllarda da devam edeceği düşünülmektedir. Dolayısıyla bu çalışmalara ilişkin ortak bir payda oluşturmak adına, çalışmada yapılan içerik analizinden farklı olarak, metaanaliz veya metasentez çalışmalarının yapılması önerilebilir.

\section{KAYNAKLAR}

Acar, S. (2009). Web destekli performans tabanlı ögrenmede motivasyon stratejilerinin ögrencilerin akademik başarılarına, kalıcılıklarına ve tutumlarına etkisi. Yayınlanmamış doktora tezi, Gazi Üniversitesi Eğitim Bilimleri Enstitüsü, Ankara.

Akbaba, S. (2006). Eğitimde motivasyon. Atatürk Üniversitesi Kazım Karabekir Eğitim Fakültesi Dergisi, (13).

Aslan, A., Şılbır, L., \& Karaman, S. (2016). Motivasyonel ifadelerle zenginleştirilmiş metinlerin öğrencilerin anlama ve öz yeterlilik düzeylerine etkisi. Journal of Instructional Technologies \& Teacher Education, 5(2).

Aşıksoy, G., \& Özdamlı, F. (2016). Flipped classroom adapted to the ARCS model of motivation and applied to a physics course. Eurasia Journal of Mathematics, Science \& Technology Education, 12(6).

Bacanlı, H. (2009). Eğitim Psikolojisi (14. Bask1). Ankara: Asal Yayıncılık.

Balantekin, Y. (2014). ARCS motivasyon modeline göre tasarlanan yapılandırmacı öğrenme yaklaşımının ögrencilerin motivasyonlarına, tutumlarına ve akademik başarlarına etkisi (Doktora Tezi). YÖK Tez Merkezinden edinilmiştir (Tez no: 382054).

Balantekin, Y., \& Bilgin, A. (2017). ARCS motivasyon modeli’nin öğrencilerin motivasyonlarına, tutumlarına ve akademik başarılarına etkisi. Illköğretim Online, 16(1).

Bixler, B. (2006). Motivation and its relationship to the design of educational games. NMC. Cleveland, Ohio. Retrieved, 10(07). 
Bolliger, D. U., Supanakorn, S., \& Boggs, C. (2010). Impact of podcasting on student motivation in the online learning environment. Computers \& Education, 55(2), 714-722.

Bowen, G. A. (2009). Document analysis as a qualitative research method. Qualitative research journal, 9(2), 27-40.

Calp, Ş. (2013). Algllanan akademik yeterlik ve algllanan özerklik desteğinin özerk akademik motivasyon ve akademik başarıyla ilişkisi (Doktora Tezi). Yükseköğretim Kurulu Ulusal Tez Merkezi’nden edinilmiştir. (Tez No. $356655)$.

Cengiz, E. (2009). ARCS motivasyon modelinin fen ve teknoloji dersinde öğrencilerin başarısına ve öğrenmenin kalıcı̆̆ına etkisi (Yüksek Lisans Tezi). YÖK Tez Merkezi (Tez no: 238099).

Cengiz, E., \& Aslan, A. (2012). ARCS motivasyon modelinin vücudumuzdaki sistemler ünitesinde akademik başarı ve öğrenmenin kalıcılığına etkisi. Kastamonu Ĕ̆itim Dergisi, 20(3), 883-896.

Çetin, Ü. (2007). ARCS motivasyon modeli uyarınca tasarlanmış eğitim yazılımı ile yapılan öğretimle geleneksel öğretimin öğrencilerin başarısı ve öğrenmenin kalıcılığı açısından karşılaştırılması (Yüksek lisans tezi). YÖK Tez Merkezinden edinilmiştir. (Tez no: 189745).

Çiftçi, S. (2006). Sosyal bilgiler ögrretiminde proje tabanlı öğrenmenin öğrencilerin akademik risk alma düzeylerine, problem çözme becerilerine, erişilerine, kalıcılı̆̆a ve tutumlarına etkisi (Doktora tezi). YÖK Ulusal Tez Merkezi'nden edinilmiştir (Tez No: 189321).

Deci, E. L., \& Ryan, R. M. (1985) Intrinsic motivation and self-determination in human behavior. New York: Plenum.

Demircioğlu, H., \& Geban, Ö. (1996). Fen bilgisi öğretiminde bilgisayar destekli öğretim ve geleneksel problem çözme etkinliklerinin ders başarısı bakımından karşılaştırılması. Hacettepe Üniversitesi Eğitim Fakültesi Dergisi, 12(12).

Ergin, A., \& Karataş, H. (2018). Üniversite öğrencilerinin başarı odaklı motivasyon düzeyleri. Hacettepe Üniversitesi Eğitim Fakültesi Dergisi, 33(4), 868-887.

Ersoy, H., Duman, E., \& Semiral, Ö. (2016). Artırılmış gerçeklik ile motivasyon ve başarı: deneysel bir çalışma. Journal of Instructional Technologies \& Teacher Education, 5(1).

Göktaş, Y., Küçük, S., Aydemir, M., Telli, E., Arpacık, Ö., Yıldırım, G., \& Reisoğlu, İ. (2012). Türkiye’de eğitim teknolojileri araştırmalarındaki eğilimler: 2000-2009 dönemi makalelerinin içerik analizi. Kuram ve Uygulamada Ĕgitim Bilimleri Dergisi, 12(1), 177-199.

Güven, G., \& Sülün, Y. (2012). Bilgisayar destekli öğretimin 8. sınıf fen ve teknoloji dersindeki akademik başarıya ve öğrencilerin derse karşı tutumlarına etkisi. Türk Fen Ĕ̈itimi Dergisi, 9(1), 68-79.

Güven,M., Aslan, B.,\& Akyol, Y.E. (2017). Türkiye'de psikolojik danışma ve rehberlik alanında yapılan doktora tezlerinin incelenmesi (2000-2016). Eğitim ve Öğretim Araştırmaları Dergisi, 6(3), 136-147.

Higbee, J.L. (1999). Affective and cognitive factors related to mathematics achievement. Journal of Developmental Education. 23(1), 8-15.

Huang, Y. M., Huang, S. H., \& Wu, T. T. (2014). Embedding diagnostic mechanisms in a digital game for learning mathematics. Educational Technology Research and Development, 62(2), 187-207.

Karakis, H., Karamete, A., \& Okçu, A. (2016). The effects of a computer-assisted teaching material, designed according to the assure instructional design and the ARCS model of motivation, on students' achievement levels in a mathematics lesson and their resulting attitudes. European Journal of Contemporary Education, 15(1), 105113.

Karasözen, B., Bayram, Ö. G., \& Zan, B. U. (2011). WoS ve Scopus veri tabanlarının karşılaştırması. Türk Kütüphaneciliği, 25(2), 238-260.

Karslı, G. (2015). ARCS motivasyon yönteminin 8. sinıf hücre bölünmesi ve kalıtım ünitesinde ögrencilerin motivasyonu başarısı ve tutumlarına etkisi (Yüksek Lisans Tezi). YÖK Tez Merkezi (Tez no: 415440).

Keller, J. M. (1979). Motivation and instructional design: A theoretical perspective. Journal of instructional development, 2(4), 26.

Keller, J. M. (1983). Motivational design of instruction. Instructional design theories and models: An overview of their current status, 1, 383-434.

Keller, J. M. (1987a). Strategies for stimulating the motivation to learn. Performance Improvement, 26(8), 1-7.

Keller, J. M. (1987b). Development and use of the ARCS model of instructional design. Journal of instructional development, 10(3), 2.

Keller, J. M. (1987c). IMMS: Instructional materials motivation survey. Florida State University.

Keller, J. M. (1999). Using the ARCS motivational process in computer-based instruction and distance education. New directions for teaching and learning, 1999(78), 37-47.

Keller, J. M. (2000). How to integrate learner motivation planning into lesson planning: The ARCS model approach. VII Semanario, Santiago, Cuba, 1-13.

Keller, J. M. (2008). First principles of motivation to learn and e3-learning. Distance Education, 29(2), 175-185.

Keller, J. M. (2010). The ARCS model of motivational design. In Motivational design for learning and performance (pp. 43-74). Springer US.

Keller, J., \& Suzuki, K. (2004). Learner motivation and e-learning design: A multinationally validated process. Journal of educational Media, 29(3), 229-239.

Kim, C., \& Keller, J. M. (2011). Towards technology integration: The impact of motivational and volitional email messages. Educational Technology Research and Development, 59(1), 91-128. 
Korucu, A. T., Usta, E., \& Atun, H. (2017). Teknolojik pedagojik alan bilgisi üzerine yapılan 2010-2016 dönemi araştırmalardaki eğilimler. Amasya Üniversitesi Ĕ̈itim Fakültesi Dergisi, 6(1), 104-133.

Kula Wassink, F., \& Sadi, Ö. (2016). Türkiye'de fen bilimleri eğitimi yönelimleri: 2005 ile 2014 yılları arası bir içerik analizi. Illkögretim Online Dergisi, 15(2), 594-614.

Li, K., \& Keller, J. M. (2018). Use of the ARCS model in education: A literature review. Computers \& Education, 122, 54-62.

Malone, T. (8). Lepper (1987). Making Learning Fun: A Taxonomy of Intrinsic Motivations for Learning. Aptitude, Learning, and Instruction, 3.

Means, T. B., Jonassen, D. H., \& Dwyer, F. M. (1997). Enhancing relevance: Embedded ARCS strategies vs. purpose. Educational Technology Research and Development, 45(1), 5-17.

Cohen, L., Manion, L., Morrison, K., \& Morrison, R. B. (2007). Research methods in education" Routledge.

Ono, Y., \& Ishihara, M. (2012). Integrating mobile-based individual activities into the Japanese EFL classroom. International Journal of Mobile Learning and Organisation, 6(2), 116-137.

Ryan, R. M., \& Deci, E. L. (2000). Intrinsic and extrinsic motivations: Classic definitions and new directions. Contemporary educational psychology, 25(1), 54-67.

Saracaloğlu, A. S., Gündoğdu, K., Altın, M., Aksu, N., Kozağaç, Z. B.,\& Koç, B. (2013). Yaratıcı düşünme becerisi konusunda 2000 yılı ve sonrasında yayımlanmış makalelerin incelenmesi. Adnan Menderes Üniversitesi Ĕ̆itim Fakültesi Ĕgitim Bilimleri Dergisi, 5(2), 62-74.

Sevgi, H. M. (2016). Üniversite öğrencilerinin bilimsel araştırma eğilimlerinin belirlenmesi. Selçuk Üniversitesi Sosyal ve Teknik Araştırmalar Dergisi, (12), 44-53.

Song, H. S., Kalet, A. L., \& Plass, J. L. (2016). Interplay of prior knowledge, self-regulation and motivation in complex multimedia learning environments. Journal of Computer Assisted Learning, 32(1), 31-50.

Su, C. H., \& Cheng, C. H. (2013). 3D game-based learning system for improving learning achievement in software engineering curriculum. Turkish Online Journal of Educational Technology-TOJET, 12(2), 1-12.

Svinicki, M., \& McKeachie, W. J. (2011). Experiential learning: Case-based, problem-based, and realitybased. Teaching tips: Strategies, research and theory for college and university teachers (13th ed.). Belmont, CA: Wadsworth Cengage Learning.

Thaer, A., \&Thaer, G. (2016). The effect of ARCS motivational model on achievement motivation and academic achievement of the tenth grade students. The New Educational Review, 43(1), 68-77.

Wlodkowski, R.J. (1985). Enhancing adult motivation to learn: A guide to improving instruction and increasing learner achievement, SF: Jossey-Bass Publishers, USA.

Wlodkowski, R.J. (1999). Enhancing adult motivation to learn: a comprehensive guide for all adults, San Francisco, CA: Jossey-Bass Inc., USA.

Yıldırım, A.,\& Şimşek, H. (2016). Sosyal bilimlerde nitel araştırma yöntemleri (10. Baskl). Ankara: Seçkin Yay.

Yüksel, G. (2011). Öğrenme için motivasyon. M. Ç. Özdemir (Ed.), Sınıf yönetimi içinde (s. 17-43). Ankara: Pegem Akademi Yayıncilık.

Zhang, W. (2017). Design a civil engineering micro-lecture platform based on the ARCS model perspective. International Journal of Emerging Technologies in Learning (iJET), 12(01), 107-118.

Zheng, L. (2016). The effectiveness of self-regulated learning scaffolds on academic performance in computer-based learning environments: a meta-analysis. Asia Pacific Education Review, 17(2), 187-202.

\section{Ek Kaynaklar: Araştırma Kapsamındaki Makaleler}

Acar, S., \& Ünsal Köse, N.Ö. (2015). Acar metoda göre on parmak f klavye öğrenenlerin derse ve öğretim materyaline ilişkin ilgi düzeylerini belirlemeye yönelik bir araştırma. PJESS, 2(2), 48-66.

Alekhya, N., Prabhu Kishore, N. (2018). Application of ARCS model and motivational design in engineering subjects - a case study. International Journal of Mechanical and Production Engineering Research and Development. $8(1), 27-34$

Annamalai, S. (2016). Implementing ARCS model to design a motivating multimedia e-book for polytechnic esl classroom. journal of telecommunication, Electronic and Computer Engineering (JTEC), 8(8), 57-60.

Arora, A. S., \& Sharma, A. (2018). Integrating the ARCS Model with Instruction for Enhanced Learning. Journal of Engineering Education Transformations, 32(1), 85-89.

Arslan Buyruk, A., Erdoğan, P., Çavuşoğlu Deveci, C., \& Yücel Toy, B. (2018). Motivasyon modeli ile zenginleştirilmiş anlamaya dayalı öğretim tasarımının öğrencilerin ingilizce konuşma becerisine ve motivasyonlarına etkisi: tasarım tabanlı bir araştırma. Journal of Higher Education \& Science, 8(1).

Aslan, A., Şılbır, L., \& Karaman, S. (2016). Motivasyonel ifadelerle zenginleştirilmiş metinlerin öğrencilerin anlama ve öz yeterlilik düzeylerine etkisi. Journal of Instructional Technologies \& Teacher Education, 5(2).

Astleitner, H., \& Lintner, P. (2004). The Effects of ARCS-Strategies on Self-Regulated Learning with Instructional Texts. E-Journal of instructional science and technology, 7(1), n1.

Aşıksoy, G., \& Özdamlı, F. (2016). Flipped classroom adapted to the ARCS model of motivation and applied to a physics course. Eurasia Journal of Mathematics, Science \& Technology Education, 12(6).

Atasoy, B., Tosik-Gün, E., \& Kocaman-Karoğlu, A. (2017). İlköğretim öğrencilerinin artırılmış gerçeklik uygulamalarına karşı tutumlarının ve güdülenme durumlarının belirlenmesi. Journal of Kirsehir Education Faculty, 18(2). 
Bacca, J., Baldiris, S., \& Ramon Fabregat, K. (2018). Insights into the factors influencing student motivation in augmented reality learning experiences in vocational education and training. Frontiers in psychology, 9.

Balantekin, Y., \& Bilgin, A. (2017). ARCS motivasyon modeli’nin öğrencilerin motivasyonlarına, tutumlarına ve akademik başarılarına etkisi. İlköğretim Online, 16(1).

Bolliger, D. U., Supanakorn, S., \& Boggs, C. (2010). Impact of podcasting on student motivation in the online learning environment. Computers \& Education, 55(2), 714-722.

Cengiz, E., \& Aslan, A. (2012). ARCS motivasyon modelinin vücudumuzdaki sistemler ünitesinde akademik başarı ve öğrenmenin kalıcılığına etkisi. Kastamonu Eğitim Dergisi, 20(3), 883-896.

Chang, C. S., Liu, E. Z. F., Sung, H. Y., Lin, C. H., Chen, N. S., \& Cheng, S. S. (2014). Effects of online college student's Internet self-efficacy on learning motivation and performance. Innovations in education and teaching international, 51(4), 366-377.

Chang, C., Chang, C. K., \& Shih, J. L. (2016). Motivational strategies in a mobile inquiry-based language learning setting. System, 59.

Chang, M. M., \& Lehman, J. D. (2002). Learning foreign language through an interactive multimedia program: An experimental study on the effects of the relevance component of the ARCS model. CALICO journal, 81-98.

Chang, N. C., \& Chen, H. H. (2015). A motivational analysis of the ARCS model for information literacy courses in a blended learning environment. Libri, 65(2), 129-142.

Chang, Y. H., Hwang, J. H., Fang, R. J., Lu, Y. T., \& Lin, Y. K. (2017). A kinect-and game-based interactive learning system. Eurasia Journal of Mathematics, Science and Technology Education, 13(8), 4897-4914.

ChanLin, L. J. (2009). Applying motivational analysis in a Web-based course. Innovations in Education and Teaching International, 46(1).

Chen, C. C., \& Chen, C. Y. (2018). Exploring the effect of learning styles on learning achievement in a uMuseum. Interactive Learning Environments, 26(5), 664-681.

Chen, Y. T. (2014). A study to explore the effects of self-regulated learning environment for hearing-impaired students. Journal of computer assisted learning, 30(2), 97-109.

Chin, K. Y., Lee, K. F., \& Chen, Y. L. (2018). Using an interactive ubiquitous learning system to enhance authentic learning experiences in a cultural heritage course. Interactive Learning Environments, 26(4), 444-459.

Chung-Ho, S. U., \& Cheng, C. H. (2013). 3D game-based learning system for improving learning achievement in software engineering curriculum. TOJET: The Turkish Online Journal of Educational Technology, 12(2).

Cook, D. A., Beckman, T. J., Thomas, K. G., \& Thompson, W. G. (2009). Measuring motivational characteristics of courses: applying Keller's instructional materials motivation survey to a web-based course. Academic Medicine, 84(11).

Çağıltay, N. E., Ozcelik, E., \& Ozcelik, N. S. (2015). The effect of competition on learning in games. Computers \& Education, 87, 35-41.

Çetin, Ü., \& Mahiroğlu, A. (2015). ARCS motivasyon modeli uyarınca tasarlanmış eğitim yazılımının öğrencilerin akademik başarısına ve öğrenmenin kalıcılığına etkisi. Ahi Evran Üniversitesi Kırşehir Eğitim Fakültesi Dergisi, 9(3), 101-112.

Çolakoglu, O. M., \& Akdemir, O. (2012). Motivational measure of the instruction compared: instruction based on the ARCS motivation theory vs traditional instruction in blended courses. Turkish Online Journal of Distance Education, 11(2).

De Carvalho, C. F. G., Coutinho, R. F., de Araujo Lima, I. D., de Leon, C. G. P., Ribeiro, L. M., Vieira, G. B., ... \& dos Santos, S. R. (2018). Evaluation of board game about 1mmunopreventable diseases for higher education in health course. Creative Education, 9(05).

Dede, Y. (2003). ARCS motivasyon modeli’nin öğrencilerin matematiğe yönelik motivasyonlarına etkisi. Pamukkale Üniversitesi Eğitim Fakültesi Dergisi, 2(14), 173-182.

Derbali, L., \& Frasson, C. (2012). Assessment of learners' motivation during interactions with serious games: a study of some motivational strategies in food-force. Advances in Human-Computer Interaction, 2012, 5.

Di Serio, Á., Ibáñez, M. B., \& Kloos, C. D. (2013). Impact of an augmented reality system on students' motivation for a visual art course. Computers \& Education, 68, 586-596.

Dinçer, S. (2017). Bilgisayar destekli öğretimde bilgisayar okuryazarlığının, motivasyonun ve öz yeterliliğin öğrenme başarısı üzerindeki etkisi: değişkenlerin araştırma süresi ile incelenmesi. Uluslararası Eğitim Programları ve Öğretim Çalışmalarn Dergisi, 7(14).

Dinçer, S., \& Doğanay, A. (2016). Öğretim materyali'ne ilişkin motivasyon ölçeği (ömmö) Türkçe uyarlama çalışması. Illkögretim Online, 15(4).

Donmuş, A. G. V., \& Gürol, M. (2014). The Effect of Educational Computer Games on Student Motivation in Learning English. e-International Journal of Educational Research, 5(4).

Feng, S. L., \& Tuan, H. L. (2005). Using ARCS model to promote 11th graders' motivation and achievement in learning about acids and bases. International Journal of Science and Mathematics Education, 3(3), 463-484.

Gedik, N., Hanci-Karademirci, A., Kursun, E., \& Cagiltay, K. (2012). Key instructional design issues in a cellular phone-based mobile learning project. Computers \& Education, 58(4), 1149-1159.

Giannakas, F., Kambourakis, G., Papasalouros, A., \& Gritzalis, S. (2016). Security education and awareness for k-6 going mobile. International Journal of Interactive Mobile Technologies (iJIM), 10(2), 41-48. 
Güvenç, H. (2015). The Relationship between teachers' motivational support and engagement versus disaffection. Educational Sciences: Theory and Practice, 15(3), 647-657.

Hakkari, F., Yeloğlu, T., Tüysüz, C., \& İlhan, N. (2017). Zenginleştirilmiş kitap (z-kitap) kullanımı için dokuzuncu sınıf kimya dersi "kimyasal türler arası etkileşimler” ünitesi ile ilgili materyal geliştirme ve geliştirilen materyalin etkisinin incelenmesi. Ë̆itim ve Bilim, 42(192).

Hamzah, W. M. A. F. W., Ali, N. H., Saman, M. Y. M., Yusoff, M. H., \& Yacob, A. (2015). Influence of gamification on students' motivation in using e-learning applications based on the motivational design model. International Journal of Emerging Technologies in Learning (iJET), 10(2), 30-34.

Hodges, C. B., \& Kim, C. (2013). Improving college students' attitudes toward mathematics. TechTrends, 57(4).

Hong, Z. W., Huang, Y. M., Hsu, M., \& Shen, W. W. (2016). Authoring robot-assisted instructional materials for 1mproving learning performance and motivation in EFL classrooms. Educational Technology \& Society, 19(1).

$\mathrm{Hu}$, A., Shewokis, P. A., Ting, K., \& Fung, K. (2016). Motivation in computer-assisted instruction. The Laryngoscope, 126(S6).

Huang, D. W., Diefes-Dux, H., Imbrie, P. K., Daku, B., \& Kallimani, J. G. (2004, October). Learning motivation evaluation for a computer-based instructional tutorial using ARCS model of motivational design. In Frontiers in Education, 2004. FIE 2004. 34th Annual (pp. T1E-30). IEEE.

Huang, W. D., \& Oh, E. G. (2018). Motivational support from digital game-based learning environments (DGBLEs) for scientific topics designed by novice end users. Educational Media International, 1-14.

Huang, W. H., Huang, W. Y., \& Tschopp, J. (2010). Sustaining iterative game playing processes in DGBL: The relationship between motivational processing and outcome processing. Computers \& Education, 55(2).

Huang, W., Huang, W., Diefes-Dux, H., \& Imbrie, P. K. (2006). A preliminary validation of Attention, Relevance, Confidence and Satisfaction model-based Instructional Material Motivational Survey in a computer-based tutorial setting. British Journal of Educational Technology, 37(2), 243-259.

Huang, Y. M., Huang, S. H., \& Wu, T. T. (2014). Embedding diagnostic mechanisms in a digital game for learning mathematics. Educational Technology Research and Development, 62(2), 187-207.

Huett, J. B., Kalinowski, K. E., Moller, L., \& Huett, K. C. (2008). Improving the motivation and retention of online students through the use of ARCS-based e-mails. The Amer. Jrnl. of Distance Education, 22(3), 159-176.

Huett, J. B., Moller, L., Young, J., Bray, M., \& Huett, K. C. (2008). Supporting the distant student: The effect of ARCS-based strategies on confidence and performance. Quarterly Review of Distance Education, 9(2), 113.

Hung, H. C., Shwu-Ching Young, S., \& Lin, K. C. (2018). Exploring the effects of integrating the iPad to improve students' motivation and badminton skills: a WISER model for physical education. Technology, Pedagogy and Education, 27(3).

Hung, I. C., Chao, K. J., Lee, L., \& Chen, N. S. (2013). Designing a robot teaching assistant for enhancing and sustaining learning motivation. Interactive Learning Environments, 21(2), 156-171.

Izmirli, S., \& Sahin Izmirli, O. (2015). Factors motivating preservice teachers for online learning within the context of ARCS motivation model. Turkish Online Journal of Distance Education, 16(2), 56-68.

Jeon, K., Jarrett, O. S., \& Ghim, H. D. (2014). Project-based learning in engineering education: is it motivational?. International Journal of Engineering Education, 30(2), 438-448.

Jin, K. A. (2013). Research on the influence of perceived interest on digital textbook learning motivation. International Journal of Multimedia and Ubiquitous Engineering, 8(6), 237-244.

Juan, Y. K., \& Chao, T. W. (2015). Game-based learning for green building education. Sustainability, 7(5), 55925608.

Jung, I., \& Hong, S. (2014). An elaborated model of student support to allow for gender considerations in Asian distance education. The International Review of Research in Open and Distributed Learning, 15(2).

Kaneko, K., Saito, Y., Nohara, Y., Kudo, E., \& Yamada, M. (2018). Does physical activity enhance learning performance?: learning effectiveness of game-based experiential learning for university library instruction. The Journal of Academic Librarianship.

Karakis, H., Karamete, A., \& Okçu, A. (2016). The effects of a computer-assisted teaching material, designed according to the assure instructional design and the ARCS model of motivation, on students' achievement levels in a mathematics lesson and their resulting attitudes. European Journal of Contemporary Education, 15(1).

Karataş, K., Ardıç, T., \& İsmet, K. A. Y. A. (2016). ARCS motivasyon modeline dayalı öğretim ölçeği geçerlik ve güvenirlik çalışması. Kastamonu Ĕ̌itim Dergisi, 24(4).

Karimi, M. N., \& Hosseini Zade, S. S. (2018). Teachers' use of motivational strategies: effects of a motivationoriented professional development course. Innovation in Language Learning and Teaching, 1-11.

Karoulis, A. (2011). On motivation to apply ODL in adult teachers' education. Informatics in Education, 10(1).

Kayak, S., \& Mahıroglu, A. (2010). ARCS güdüleme modeline göre tasarlanan eğitsel yazılımın öğrenmeye etkisi. Journal of Turkish Educational Sciences, 8(1).

Kebritchi, M., Hirumi, A., \& Bai, H. (2010). The effects of modern mathematics computer games on mathematics achievement and class motivation. Computers \& education, 55(2), 427-443.

Kikuchi, H. (2006). Motivational factors affecting online learning by Japanese MBA students. Australasian Journal of Educational Technology, 22(3). 
Kim, C., \& Keller, J. M. (2008). Effects of motivational and volitional email messages (MVEM) with personal messages on undergraduate students' motivation, study habits and achievement. British Journal of Educational Technology, 39(1).

Kim, C., \& Keller, J. M. (2011). Towards technology integration: The impact of motivational and volitional email messages. Educational Technology Research and Development, 59(1), 91-128.

Klampfer, A., \& Köhler, T. (2015). Learners' and teachers' motivation toward using e-portfolios. An empirical investigation. International Journal of Continuing Engineering Education and Life Long Learning, 25(2), 189207.

Kurt, P. Y., \& Kurt, H. (2018). Instructional practices that motivate students to learn english. Journal of Education, (14), 119-130.

Kutu, H., \& Sozbilir, M. (2011). Öğretim materyalleri motivasyon anketinin Türkçeye uyarlanması: Güvenirlik ve geçerlik çalışması. Necatibey Ĕgitim Fakültesi Elektronik Fen ve Matematik Eğitimi Dergisi, 5(1).

Li, K., \& Moore, D. R. (2018). Motivating Students in Massive Open Online Courses (MOOCs) Using the Attention, Relevance, Confidence, Satisfaction (ARCS) Model. Journal of Formative Design in Learning, 1-12.

Li, M., \& Ren, Y. (2018). A multimedia teaching model for "sports statistics" based on ARCS motivation theory. International Journal of Emerging Technologies in Learning (iJET), 13(09), 15-28.

Liao, H. C., \& Wang, Y. H. (2008). Applying the ARCS motivation model in technological and vocational education. Contemporary Issues in Education Research, 1(2), 53-58.

Liu, T. Y., \& Chu, Y. L. (2010). Using ubiquitous games in an English listening and speaking course: Impact on learning outcomes and motivation. Computers \& Education, 55(2), 630-643.

Loorbach, N., Karreman, J., \& Steehouder, M. (2013). Verification steps and personal stories in an instruction manual for seniors: effects on confidence, motivation, and usability. IEEE transactions on professional communication, 56(4).

Loorbach, N., Peters, O., Karreman, J., \& Steehouder, M. (2015). Validation of the instructional materials motivation survey (1mms) in a self-directed instructional setting aimed at working with technology. British journal of educational technology, 46(1), 204-218.

Lu, S. J., Liu, Y. C., Chen, P. J., \& Hsieh, M. R. (2018). Evaluation of AR embedded physical puzzle game on students' learning achievement and motivation on elementary natural science. Interactive Learning Environments, 1-13.

Maeng, U., \& Lee, S. M. (2015). EFL teachers' behavior of using motivational strategies: The case of teaching in the Korean context. Teaching and Teacher Education, 46, 25-36.

Mathew, J. (2018). Effectiveness of attention relevance confidence satisfaction model on mathematics anxiety among students at secondary level. international journal of scientific research, 6(5).

Means, T. B., Jonassen, D. H., \& Dwyer, F. M. (1997). Enhancing relevance: Embedded ARCS strategies vs. purpose. Educational Technology Research and Development, 45(1), 5-17.

Mohamad, S. N. A., Embi, M. A., \& Nordin, N. M. (2016). Designing e-portfolio with ARCS motivational design strategies to enhance self-directed learning. Higher Education Studies, 6(4), 138-145.

Munawarah, J., Kasim, U., \& Daud, B. (2018). Improving speaking sub-skills by using the attention, relevance, confidence and satisfaction (ARCS) model. English Education Journal, 9(3), 356-376.

Mustami, M. K., \& Safitri, D. (2018). The effects of numbered heads together-assurance relevance interest assessment satisfaction on students' motivation. International Journal of Instruction, 11(3), 123-134.

Nguyen, G. N. T. (2015). A case study of students' motivation in college algebra courses. Community College Journal of Research and Practice, 39(8), 693-707.

Novak, E. (2014). Toward a mathematical model of motivation, volition, and performance. Computers \& Education, 74.

Ono, Y., \& Ishihara, M. (2012). Integrating mobile-based individual activities into the Japanese EFL classroom. International Journal of Mobile Learning and Organisation, 6(2), 116-137.

Orji, R., Reilly, D., Oyibo, K., \& Orji, F. A. (2018). Deconstructing persuasiveness of strategies in behaviour change systems using the ARCS model of motivation. Behaviour \& Information Technology, 1-17.

Ortiz, O. O., Franco, J. Á. P., Garau, P. M. A., \& Martín, R. H. (2017). Innovative mobile robot method: improving the learning of programming languages in engineering degrees. IEEE Transactions on Education, 60(2), 143148.

Özdemir, M., Izmirli, S., \& Sahin-Izmirli, O. (2016). The effects of captioning videos on academic achievement and motivation: reconsideration of redundancy principle in instructional videos. Journal of Educational Technology \& Society, 19(4).

Özdemir, M., Yıldız, A. M \& (2015). The effect of educational videos presented in two different content stream on motivation and achievement of students with visual learning styles. Eğitimde Kuram ve Uygulama, 12(1).

Özer, H. H., \& Bicen, H. (2017). The Effect of gamified learning environment on student success. International Journal of Scientific Study, 5(8), 108-113.

Pittenger, A., \& Doering, A. (2010). Influence of motivational design on completion rates in online self-study pharmacy-content courses. Distance Education, 31(3), 275-293. 
Proske, A., Roscoe, R. D., \& McNamara, D. S. (2014). Game-based practice versus traditional practice in computerbased writing strategy training: effects on motivation and achievement. Educational Technology Research and Development, 62(5), 481-505.

Putri, A. U., Rusyati, L., \& Rochintaniawati, D. (2018). The 1mpact of problem-solving model on students' concept mastery and motivation in learning heat based on gender. Journal of Science Learning, 1(2), 71-76.

Qian, X. (2014). Construction and application of an educational game based on the ARCS model. The World Transactions on Engineering and Technology Education Journal, 12(21), 236-241. Wyss, J., Lee, S. E., Domina, T., \& MacGillivray, M. (2014).

Reisoglu, I., Yilmaz, R., Çoban, M., Topu, F. B., Karkus, T., \& Göktas, Y. (2015). Üç boyutlu sanal dünyalardaki tasarım ögelerinin motivasyon boyutlari açısından incelenmesi. Pegem Egitim ve Ogretim Dergisi, 5(3), 257.

Reynolds, K. M., Roberts, L. M., \& Hauck, J. (2017). Exploring motivation: integrating the ARCS model with instruction. Reference Services Review, 45(2), 149-165.

Roberts, L. (2017). Research in the real world: Improving adult learners web search and evaluation skills through motivational design and problem-based learning. College \& Research Libraries, 78(4), 527.

Sánchez-Mena, A., Martí-Parreño, J., \& Aldás-Manzano, J. (2017). The role of perceived relevance and attention in teachers' attitude and intention to use educational video games. International Journal of Emerging Technologies in Learning (iJET), 12(03), 154-168.

Sevier, C., Chyung, S. Y., Callahan, J., \& Schrader, C. (2012). What value does service learning have on introductory engineering students' motivation and abet program outcomes?. Journal of STEM Education.

Small, R. V., Zakaria, N., \& El-Figuigui, H. (2004). Motivational aspects of information literacy skills instruction in community college libraries. College \& Research Libraries, 65(2), 96-121.

Song, S. H., \& Keller, J. M. (2001). Effectiveness of motivationally adaptive computer-assisted instruction on the dynamic aspects of motivation. Educational technology research and development, 49(2), 5.

Sözbilir, M. (2011). Yaşam temelli ARCS öğretim modeliyle 9. sınıf kimya dersi "hayatımızda kimya" ünitesinin öğretimi. ondokuz mayls üniversitesi eğitim fakültesi dergisi, 30(1).

$\mathrm{Su}, \mathrm{C}$. H. (2017). The effects of students' learning anxiety and motivation on the learning achievement in the activity theory based gamified learning environment. Eurasia Journal of Mathematics, Science \& Technology Education, 13(5).

Su, C. H., \& Cheng, C. H. (2015). A mobile gamification learning system for improving the learning motivation and achievements. Journal of Computer Assisted Learning, 31(3), 268-286.

Sulısworo, D., Sulıstıyo, E. N., \& Akhsan, R. N. (2017). The motivation impact of open educational resources utilization on physics learning using quipper school app. Turkish Online Journal of Distance Education, 18(4).

Sultana, N., \& Khalil, A. (2017). Application of ARCS model for utilizing blogs to enhance learners' motivation in higher education. Pakistan Journal of Distance \& Online Learning, 3(2), 53-70.

Suzuki, K., Nishibuchi, A., Yamamoto, M., \& Keller, J. M. (2004). Development and evaluation of website to check instructional design based on the ARCS motivation model. Information and Systems in Education, 2(1), 63-69.

Şanal, S. Ö., \& Türel, Y. K. Fonksiyonlar konusunun ARCS motivasyon modeli temelinde geliştirilen etkileşimli ekitap ile öğretimi: eylem araştırması. Ĕgitim Teknolojisi Kuram ve Uygulama, 8(1), 121-140.

Taha, A. M., \& Thang, S. M. (2014). Exploring motivational design and motivation types facilitated by an online support system for learning literature. GEMA Online ${ }^{\circledR}$ Journal of Language Studies, 14(2).

Tahiroğlu, M. (2015). ARCS motivasyon modeli'nin İlkokul 4. sınıf öğrencilerinin sosyal bilgiler dersine yönelik motivasyonlarına ve başarı düzeylerine etkisi. Zeitschrift für die Welt der Türken, 7(2), 261-285.

Thaer, A., \&Thaer, G. (2016). The effect of ARCS motivational model on achievement motivation and academic achievement of the tenth grade students. The New Educational Review, 43(1), 68-77.

Thurston, T. N. (2018). Design case: implementing gamification with ARCS to engage digital natives. Journal on Empowering Teaching Excellence, 2(1), 5.

Tlili, A., Essalmi, F., \& Jemni, M. (2017). Towards applying Keller's ARCS model and learning by doing strategy in classroom courses. In Innovations in Smart Learning (pp. 189-198). Springer, Singapore.

Tsai, C. H., Kuo, Y. H., Chu, K. C., \& Yen, J. C. (2015). Development and evaluation of game-based learning system using the Microsoft Kinect sensor. International Journal of Distributed Sensor Networks, 11(7), 498560.

Tugun, V. (2018). Impacts and opinions on the technology self-sufficiency of the students who are coding education in the flipped classroom adapted to the ARCS motivation model. Tem Journal-Technology Educatıon Management Informatics, 7(2), 366-371.

Turan, T., \& Şeker, B. S. (2018). The effect of digital stories on fifth-grade students' motivation. Journal Of Educatıon And Future, (13).

Türel, Y. K., \& Sanal, S. O. (2018). The effects of an ARCS based e-book on student's achievement, motivation and anxiety. Computers \& Education, 127, 130-140.

Varol, F., Seda, Ö. Z. E. R., \& Türel, Y. K. (2014). ARCS motivasyon modeline yönelik tasarlanan z-kitaplara ilişkin görüşler. Journal of Instructional Technologies \& Teacher Education, 3(3).

Wei, X., Weng, D., Liu, Y., \& Wang, Y. (2015). Teaching based on augmented reality for a technical creative design course. Computers \& Education, 81, 221-234.

Wu, P. L., Tsai, C. H., Yang, T. H., Huang, S. H., \& Lin, C. H. (2012). Using ARCS model to promote technical and vocational college students' motivation and achievement. International Journal of Learning, 18(4). 
$\mathrm{Wu}, \mathrm{T}$. T. (2018). Improving the effectiveness of English vocabulary review by integrating ARCS with mobile gamebased learning. Journal of Computer Assisted Learning, 34(3), 315-323.

Wyss, J., Lee, S. E., Domina, T., \& MacGillivray, M. (2014). Cotton island: students' learning motivation using a virtual world. Decision Sciences Journal of Innovative Education, 12(3), 219-232.

Yang, Y. F., Lee, C. I., \& Chang, C. K. (2016). Learning motivation and retention effects of pair programming in data structures courses. Education for Information, 32(3), 249-267.

Yıldız, V., Kılıç, D. (2018). İlkokul öğrencilerinin öğretmenlerine ilişkin motivasyon durumlarının ARCS modeli açısından incelenmesi. Journal of Current Researches on Social Sciences, 8 (4).

Yüzen, A., \& Karamete, A. (2016). Computer assisted educational material preparation for fourth grade primary school students' english language class in teaching numbers. European Journal of Contemporary Education, 15(1), 94-104.

Zhang, W. (2017). Design a civil engineering micro-lecture platform based on the ARCS model perspective. International Journal of Emerging Technologies in Learning (iJET), 12(01), 107-118.

Zohoorian, Z., Sadr, N. M., \& Shamabadi, F. (2018). A summative evaluation of 'prospect 1': employing the ARCS model. International Journal of Instruction, 11(3). 